Citation: Fletcher, K.J., dasNair, R. ${ }^{*}$ Macniven, J., Basu, S., \& Byrne, P. (2012). An interpretative phenomenological analysis of the patient experience of awake craniotomy: brain tumour diagnosis to discharge. British Journal of Health Psychology. 2 MAY 2012 DOI: 10.1111/j.2044-8287.2012.02079.x

\title{
An interpretative phenomenological analysis of the patient experience of awake craniotomy: Brain tumour diagnosis to discharge
}

\author{
Kimberley J. Fletcher ${ }^{1}$, Roshan das Nair ${ }^{2}$, Jamie A. B. Macniven ${ }^{3}$, \\ Surajit Basu 4 and Paul Byrne 4 \\ Trent Doctorate in Clinical Psychology, University of Nottingham, UK \\ anstitute of Work, Health and Organizations, University of Nottingham, UK \\ separtment of Clinical Psychology and Neuropsychology, Nottingham University \\ Hospitals NHS Trust, UK \\ 4Department of Neurosurgery, Nottingham University Hospitals NHS Trust, UK
}

Objectives. Previous research exploring the patient experience of awake craniotomy (AC) has yielded contrasting accounts. The current study aimed to explore the lived experience of having undergone an $\mathrm{AC}$ in the United Kingdom.

Design. This was a qualitative, semi-structured interview study. Interviews were audiorecorded and transcribed verbatim. Data were analysed using interpretative phenomenological analysis (IPA).

Methods. Seven participants (three males, four females) who had undergone an AC in the United Kingdom took part in the study. Ages ranged between 26 and 41 years old at the time of interview. Time since AC ranged from 5 months to 4 years.

Results. Participants appeared to be satisfied with, and tolerant of, the $A C$ experience. Three superordinate themes: use of self-preservation strategies prior to and during $A C$, a bizarre yet pleasant operation experience, and the need for more concrete information prior to surgery were identified. These themes appeared to be embedded in a core theme: relationship with the neurosurgeon.

Conclusions. The relationship with the neurosurgeon appears crucial to the patient experience of AC. This knowledge underscores the need for effective doctor-patient communication skills which could lead to improved delivery of care and more positive outcomes. 


\section{What is already known on this subject?}

-

Little is currently known about the patient experience of awake craniotomy in the United

Kingdom.

Previous studies have reported a satisfactory and tolerable experience (e.g. Danks et al. 1998)

however a recent exploratory study has reported an anxiety provoking experience (Palese et al. 2008).

\section{What does this study add?}

- $\quad$ This study adds to paucity of research literature exploring the patient experience of awake craniotomy in the United Kingdom.

The findings emphasize the importance of the patients' relationship with the neurosurgeon, underscoring the need for neurosurgeons to have effective communication skills when preparing patients for, and guiding patients through, the awake craniotomy procedure.

- $\quad$ The study highlights the need for better information provision in neurosurgery departments.

An estimated 6,500 people are diagnosed with a brain tumour in the United Kingdom each year (NICE, 2006). Treatment options for the safe removal of brain tumours have advanced in recent years. This is particularly relevant where the tumour is close to functionally eloquent areas of the brain, for example, motor or language areas (Meyer et al., 2001). When removing such tumours, an awake craniotomy (AC) procedure is thought to be a preferential (Meyer et al., 2001), well established, and safe technique (Costello \& Cormack, 2004; Danks, Rogers, Aglio, Gugino, \& Black, 1998).

The AC aims to resect the maximum amount of brain tumour possible while the patient is awake and fully responsive (Lanier, 2001). Advantages of AC, in contrast to traditional surgical procedure (where the patient is sedated), include minimizing the probability of damaging functionally eloquent cortex (Meyer et al., 2001) as the surgical team can assess patient responses during the procedure. In addition, AC could avoid complications caused by general anaesthesia and reduce costs (Black, 1998; Blanshard, Chung, Manninen, Taylor, \& Bernstein, 2001) through reducing length of hospital stay (Serletis \& Bernstein, 2007).

Despite the reported advantages of AC, it could be argued that little is truly understood about the patient experience (Bernstein, 2001). To date, the majority of published studies on patient experience have reported satisfaction with (Danks et al., 1998; Khu et al., 2009; Manninen, Balki, Lukitto, \& Bernstein, 2006), and tolerance of (Manninen et al., 2006; Palese, Skrap, Fachin, Visioli, \& Zannini, 2008; Sarang \& Dinsmore, 2003; Tonn, 2007; Whittle, Midgley, Georges, Pringle, \& Taylor, 2005) AC. However findings from these studies have to be considered with caution given the methodological limitations. For example, research has failed to report how participant accounts were obtained (Danks, Aglio, Gugino, \& Black, 2000; Sarang \& Dinsmore, 2003; Tonn, 2007). Where the complexity of the methodology was improved (Danks et al., 1998; Goebel, Nabavi, Schubert, \& Mehdorn, 2010; Manninen et al., 2006; Whittle et al., 2005), conclusions were potentially compromised by a lack of transparency (Manninen et al., 2006; Whittle et al., 2005), or biased through a member of the surgical team conducting data collection (Danks et al., 1998).

To provide a more comprehensive account of this experience, two studies utilized thematic analysis (Khu et al., 2009) and phenomenological analysis (Palese et al., 2008) 
to explore patient experience. Khu et al. (2009) reported positive reflections on the AC experience. This was characterized by patient satisfaction, understanding of the rationale, surprise at the novel concept, a greater concern about the disease process and trust in one's surgeon. In contrast to previous research, Palese et al. (2008) reported a tolerable but more anxiety provoking experience. Four key themes were identified: selfpreservation, working out their role in the operation, having the situation under control and seeking reassurance for themselves and others. Although a positive step forward, both studies had methodological drawbacks. These included conducting interviews prior to and following awake surgery, potentially creating a superficial split in the reporting of the experience, and asking participants directed questions (Khu et al., 2009). In addition, given that each study was conducted outside of the United Kingdom, the potential for differences in the operation procedure and clinical experience and care are high.

In light of the paucity of research in this area, the inconsistent findings and methodological constraints reported, further exploration of the patient experience of $\mathrm{AC}$ is essential. This is particularly relevant when considering the diversification of AC to remove tumours in any area of the brain (Serletis \& Bernstein, 2007) and in younger patient groups, for example, adolescents (McDougall, Rosenfeld, Wrennall, \& Harvey, 2001). As patients' experiences of AC may differ between countries, it is essential to explore the patient experience of AC in the United Kingdom. Using interpretative phenomenological analysis (IPA), the aim of this study was to broaden the evidencebase and facilitate understanding for neurosurgery teams and prospective patients about the lived experience of AC.

\section{Methods}

\section{Study design}

In this retrospective qualitative study, we used IPA (Smith, 1996) to explore patients' experiences of AC. IPA is interested in the way people make sense of unique events (Smith, 1996). In the current study, IPA was utilized to explore how people made sense of their AC experience. To achieve this, the interviewer attempted to make sense of the participant trying to make sense of their experience (Smith, Flowers, \& Larkin, 2009). 'This is referred to as the 'double hermeneutic' in phenomenological studies. IPA, as a methodology, has gained popularity in medical and healthcare research, but has not previously been used in neurosurgical studies.

\section{Participants}

Eleven potential participants who had undergone AC and met our inclusion criteria received an information pack about the study, sent out from a Department of Neurosurgery at a large UK National Health Service (NHS) teaching hospital, on behalf of the research team. Participants were included if they had undergone an AC procedure and were over 18 years of age. Given the interview-based approach of data collection, participants were excluded if they did not speak English or if they had language problems. No selection criteria were set for the time since the procedure or other medical factors. Eight participants consented to take part.

Eight interviews were conducted for this study, but one was terminated and the data withdrawn from the analysis, because the participant became distressed during the 
Table I. Interview schedule

- Tell me about your decision to have an awake craniotomy

- Having made the decision, how did you feel before the surgery? (How did you prepare yourself?)

- Having made the decision, how did you feel on the day of the surgery?

- Having made the decision, how did you feel during the surgery? (Can you tell me about your AC?)

- Can you tell me about the time after your surgery? (What did you think about the experience? What happened afterwards? Can you tell me about going home?)

- How has life changed since the AC?

Table 2. Participant information

\begin{tabular}{lclc} 
Participant pseudonym & Age at interview & Gender & Time since craniotomy (months) \\
\hline Sundeep & 28 & Male & 5 \\
Jen & 35 & Female & 32 \\
Jo & 26 & Female & 48 \\
Rachel & 28 & Female & 37 \\
Emma & 32 & Female & 36 \\
Craig & 29 & Male & 19 \\
Ben & 41 & Male & 16
\end{tabular}

interview and expressed a desire to stop the interview. This was in keeping with the ethical guidelines that the study was required to follow.

\section{Data collection}

A semi-structured interview was conducted with each participant. All interviews were conducted by KJF at the participants' homes and were audio recorded. Interview duration ranged between 46 and $70 \mathrm{~min}$. Interviews were based on an interview schedule developed by the research team (see Table 1). The schedule followed a temporal sequence to explore the experience of $\mathrm{AC}$ in its entirety. Following IPA methodology, the interview schedule was not referred to directly during the interview. The interviewer's knowledge of the schedule was sufficient to loosely follow the questions in line with interests and views offered by the participant thereby not directing the participants and permitting them to say what they felt was important to them, but at the same time maintaining a basic framework of inquiry. Prompts were employed throughout interviews to clarify questions or encourage responding. Demographic data were also collected from participants to describe the sample.

\section{Data analysis}

Audio recordings of all interviews were transcribed verbatim. Transcripts were analysed in detail by KJF and checked by RdN. Data analysis followed an adapted version of the stages of IPA (Smith et al., 2009). Initially, transcripts were read and re-read, noting down descriptive, linguistic, and conceptual comments in the right margin. Second, emerging themes were noted in the left margin. Third, themes were listed and superordinate and subordinate themes were identified. Transcripts were analysed initially on a case-by-case basis. On completion of individual transcript analysis all themes were collated, organized, and combined. During analysis the lead author did not attempt to withhold or 'bracket' previous knowledge and experience as this process is not supported by IPA. Rather, 
keeping with the lead author's epistemological frame of critical realism, previous knowledge and experience informed interpretation.

\section{Quality assurance}

Quality assurance measures (Yardley, 2000) were followed closely by the research team. Attempts were made to establish the trustworthiness of the findings (Lincoln \& Guba, 1985). Trustworthiness was sought through keeping an audit-trail of analytical decision making, and by the lead author maintaining a reflective diary. The audit-trail ensured transparency throughout the decision-making process. The journey to all themes identified can be traced through the analysis process from audio recording to write-up. This was made explicit through the provision of direct participant quotes in this article, ensuring the write-up has credibility. Furthermore, two other authors $(\mathrm{RdN}$ and JM) also appraised the coding of the data in terms of the thematic structure and content to examine whether they could 'see' what the lead researcher was seeing in the data.

The reflective diary was utilized from initial contact with participants to final writeup. This enabled the lead author to document considerations about previous knowledge and experience which may have impacted on data analysis or write-up.

\section{Research ethics}

Participation was voluntary and informed consent was obtained. Data which could reveal participant identity was made anonymous, and pseudonyms were used for the participants and those they referred to during the interviews. Audio recordings and full, anonymous, transcripts were securely stored. The study was approved by a NHS Research Ethics Committee and by a NHS Trust's Research and Development department.

\section{Results}

Seven participants (three males) completed the interviews between January and May 2010. Participants were 26-41 years of age at the time of interview. Time since AC ranged between 5 months and 4 years (Table 2). Two neurosurgeons conducted the AC procedures explored in this study.

Analysis of transcripts produced three superordinate themes: use of self-preservation strategies before and during AC, a bizarre yet pleasant operation experience, and the need for more concrete information prior to surgery. The superordinate themes were interpreted as interconnected with each other, as well as embedded in a core theme: relationship with the neurosurgeon. Figure 1 illustrates the relationship between the core theme and superordinate themes. Relationship with the neurosurgeon is central to the diagram as it was viewed as crucial to the experience of AC. During analysis all participants' accounts were taken in to consideration. However, for the purpose of this article and due to space restrictions only a few quotes have been selected to facilitate illustration of themes. 


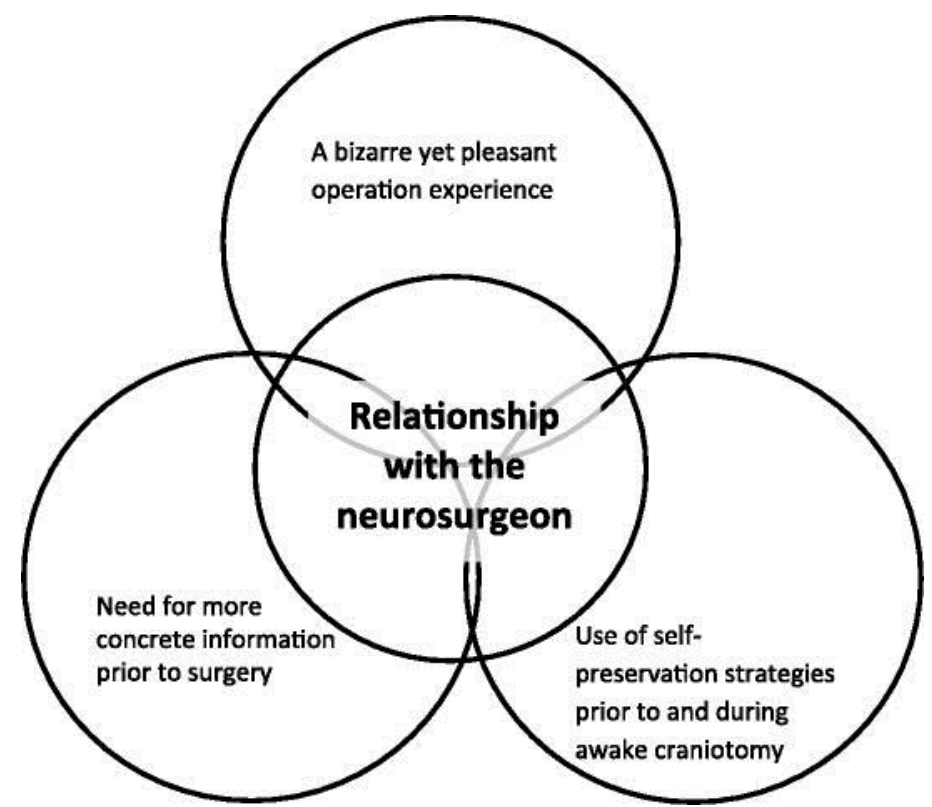

Figure I. Schematic representation of the relationship between identified themes.

\section{Use of self-preservation strategies before and during $A C$}

The first theme encompassed ideas presented by participants about their thoughts regarding the risks of the AC procedure. Participants used a variety of strategies, which could be considered defence mechanisms, for self-preservation in this process. As with other themes the relationship with the neurosurgeon was embedded within it.

It was understood that participants were aware of the potential consequences of going ahead with the AC procedure:

You could be left paralysed. I think that was quite scary at first (Jen, 1181).

I'd sort of made my decision at that particular time [of going in for AC] ... This could possibly be the last time [pause] I see anyone (Sundeep, 213).

Due to the frightening consequences, participants described coping with the experience of preparing for the AC by avoiding or distracting themselves from thinking about the operation:

I don't really think I actually thought about what they were going to do. I suppose, you know, black it out of your mind a little bit (Jen, 105).

I just thought if I don't think about it then I can't worry about it (Emma, 803).

In the above extracts, Jen and Emma described making a conscious effort not to think about the upcoming AC. In line with this, one participant described actively focusing his attention and thoughts on seeking spiritual support, and another found it beneficial to use humour to cope with the upcoming event: 
we [participant and his family] spent a lot of time praying. I felt [long pause] almost [pause] as if I wasn't there! because these sorts of things were happening, but they were happening around me. As if they were happening to somebody else! Umm detached I think is the word (Sundeep, 105).

It is scary, but it's one of those things that if you didn't laugh about it you'd cry. . . You just have to get on with it (Rachel, 206).

It was interpreted that coping through avoidance, distraction, external focus, and humour were acting as self-preservation strategies for the participants. This was illustrated by Jo, who described needing to do anything except sit and think about the AC:

I was quite frightened before [the $\mathrm{AC}$ ] ... I went back to work and stuff and yeah I suppose that helped. It meant I was just getting on with like normal normal stuff. I'm glad I did that rather than sitting at home because I think I really would have wound myself up (88).

The use of self-preservation strategies appeared to be reflected in all of the participants' decision to have the AC, which appeared to be one of the most complex life choices that participants had to make. Due to the emotional intensity of this decision, they appeared to cope with the decision by placing responsibility on the neurosurgeon:

You put your life in the hands of the [neuro]surgeon and you just trust them! (Craig, 138).

In order to place this extreme amount of trust on the neurosurgeon, it was interpreted that participants must have taken in to account their relationship with the neurosurgeon when making this decision. This appeared to be over and above the status of the neurosurgeon or the power they wielded on enforcing a decision. The decision to go through with the operation, based on the relationship with the neurosurgeon, was best articulated by Rachel and Emma:

I just said to Dr. James [neurosurgeon], I trust you whatever you think. If there wasn't that [the trust] there I think I would have questioned him a lot more (Rachel, 875).

If it wasn't somebody like that [referring to the neurosurgeon] I would have been possibly at least a bit more reluctant or perhaps wouldn't, maybe try to strive for somebody that I did feel happy with (Emma, 938).

Participants believed that they were placing their lives in the hands of the neurosurgeon. Therefore, it appeared that the relationship with the neurosurgeon was an extension of the self-preservation strategies described above. By giving the responsibility of deciding whether to go ahead with the AC to the neurosurgeon, participants were avoiding facing the implications of the decision themselves.

\section{A bizarre yet pleasant operation experience}

The relationship with the neurosurgeon described in the above theme was made explicit when considering the participant perception of the operation environment. It was understood that participants found being awake during the operation 'bizarre': 
Although bizarre, participants appeared to find the AC a fascinating and, surprisingly, a 'pleasant' experience:

I remember it being quite a pleasant experience, and certainly not frightening in any way (Jo, 197).

It was sort of quite a little pleasant experience! Most bizarre way of putting it! There was no, but there was no 'this is horrible' (Craig, 300).

To control the emotion felt during the AC, provoked by finding the AC bizarre, participants appeared to rely on their self-preservation strategies:

I think you try not to sort of think.. . about what's really going on. Then it doesn't, y'know. It's just you can't feel anything, you can't see anything (Emma, 315).

You've built up that relationship with him [neurosurgeon], and when you wake up and you hear that familiar voice, in a way, it relaxes you. I don't know if that's the right word, it does, I suppose it reassures you (Jen, 463).

Controlling emotion may have been a combination of participants adopting selfpreservation strategies, for example, Jen described drawing on the relationship she had developed with the neurosurgeon, or it could be attributed to the neurosurgical team strategically adopting distraction strategies throughout the AC:

they were all quite jokey, jovial. They were all talking to me all the time and it seemed to go really quickly. I wasn't thinking oh God! when is this going to be over?. . they're talking to you, that kept me occupied (Emma, 574).

It was felt that if the relationship with the neurosurgeon did not exist, or selfpreservation strategies were not adopted or facilitated by the neurosurgical team, participants may have focused more on the bizarre aspects of the operation and potentially suffered increased apprehension levels. Emma articulates this point:

I think he [neurosurgeon], if he had not made me feel comfortable and just and y'know quite relaxed about it all, I would have been y'know different (Emma, 927).

\section{Need for more concrete information prior to surgery}

The theme, the need for more concrete information prior to surgery, encompasses ideas presented by participants about the lack of concrete information given to them prior to the AC. Participants described the impact this had on their inability to relay information back to family and friends, and understand the operation procedure ('to find out exactly what was going to be done' (Jen, 64)), Rachel, for instance, felt that:

because a lot of questions they [family and friends] ask you, you can't answer so you, because you don't know yourself, so to have just an information pack. It would've been so much easier to just come home when they're all, everyone wants to ask you the same question 10 times, to just drop a leaflet in the hand and just say read that! (1054).

Craig discussed how the lack of concrete information impacted on his understanding of the expected outcomes:

we [Craig and his wife] didn't realize at the time but its only since our last meeting with the consultant [neurosurgeon] that although a tumour on your brain can cause you to have an epileptic fit, the scar tissue from having a tumour and having the operation, is as effective if not more effective at causing fits (Craig, 519). 
Given the participants' retrospective dissatisfaction with the lack of concrete information, yet their failure to seek out concrete information at the time, it was hypothesized that participants utilized their relationship with the neurosurgeon to compensate for the information. This relationship appeared to be bolstered by the time surgeons devoted to their patients before the surgery to explain things to them:

I'd had quite a few appointments with him [neurosurgeon] and it was quite in depth, go through quite a lot with you (Jen, 464).

He [neurosurgeon] gave lots of information ... umm so yeah I just kind of stuck with y'know what they said (Jo, 317).

Emma articulated the impact that the relationship with the neurosurgeon had on her need to seek out different opinions or more information:

I mean to be fair I felt comfortable with him [neurosurgeon] from the word go. I mean Ben [husband] sort of said y'know do you want to look for different surgeons this that and the other, somebody in [a different county], I said to be honest I can't be arsed to trail around, I said I'm, not feeling the best! I just want to get it over with (Emma, 890).

In this extract Emma discusses how the relationship she had developed with the neurosurgeon stopped her from seeking out information and opinion from elsewhere. In doing this, Emma alludes to her utilization of self-preservation strategies, for example, using the relationship with the neurosurgeon and avoiding thinking about the upcoming AC. Emma also resisted her husband's suggestion to seek further information elsewhere. Therefore, on the one hand, a lack of information appeared to facilitate participants' avoidance of information but on the other hand, as participants did not have concrete information to share with their family and friends, their self-preservation strategies appeared to be continually challenged.

\section{Discussion}

In line with previous research, the current study supports the finding that participants were satisfied with (Danks et al., 1998; Khu et al., 2009; Manninen et al., 2006), and tolerant of (Palese et al., 2008; Sarang \& Dinsmore, 2003; Whittle et al., 2005) the AC experience.

In this study, the first superordinate theme, use of self-preservation strategies before and during $A C$, illustrated how participants utilized strategies, such as avoidance, distraction, external focus, and humour, to protect them from thinking about the upcoming AC and the potential consequences associated with it. In addition it appeared that participants relied on the neurosurgeon to make their treatment decision, utilizing their relationship with the neurosurgeon itself as a self-preservation strategy.

Using self-preservation strategies in this way was discussed briefly within the theme, 'preoperative concerns: working out the intra-operative role' (Palese et al., 2008, p. 168), in a previous phenomenological study exploring the patient experience of AC in Italy. Palese et al. (2008), however, placed less emphasis on self-preservation strategies than the current study and only briefly reported that the evening prior to the AC participants wanted to keep busy or distract themselves to cope with their situation. 
Use of coping strategies for self-preservation, as in the current study, has been widely discussed. Coping has been defined as a response to a demand which is placing pressure on a person's usual resources (Lazarus, 1993). The impact of adopting coping strategies can lead to adaptation to a new situation (Lazarus \& Folkman, 1984). However, if the coping strategies are dysfunctional, patients may struggle to adapt (Canam, 1993) and their quality of life may suffer (Folkman \& Moscowitz, 2004). Other than that discussed, there is limited literature exploring coping strategies for the purpose of self-preservation prior to any type of surgery, for brain tumour populations (Spijker, Trijsburg, \& Duivenvoorden, 1997), or other serious conditions (Crumlish, 1994).

To generate research on coping strategies, the contrast between controllable and uncontrollable situations warrants further investigation. With regards to the current study, we suggest that further research should explore the use of coping strategies by brain tumour patients prior to and during the AC procedure. This would provide an evidence-base specific to the AC population. Such evidence could help to generate ideas for the facilitation of coping for prospective patients, potentially improving the AC experience (Croyle et al., 2003).

The second superordinate theme, a bizarre yet pleasant operation experience, is supported by previous research which suggests that participants are less concerned about the AC procedure in comparison to other aspects of the experience (Khu et al., 2009), such as discovering they had a brain tumour. It also demonstrates support for previous research, suggesting that participants' find staying awake a positive aspect of any operation (DeAndres, Valia, Gil, \& Bolinches, 1995). For instance, 80\% of patients who have had awake surgery before would have awake surgery again (Callesen, Bech, \& Kehlet, 2001). This said, contrasting research findings can also be found in AC literature (Palese et al., 2008).

The participants in the current study described the operation as bizarre yet pleasant. Such bizarre or surreal interpretations are consistent with previous AC literature (Khu et al., 2009). The pleasant aspect of the experience was partly attributed to the participants' relationship with the neurosurgeon in the current study. It was interpreted that participants utilized their relationship with the neurosurgeon to contain their apprehension during the procedure. Again, the utility of the relationship with the neurosurgeon in this way for $\mathrm{AC}$ is a novel finding of this study and proposes that if the participants develop a good relationship with the neurosurgeon, they may develop more trust and confidence in the neurosurgeon (Axelrod \& Dorr Goold, 2000), potentially leading to a better experience with less distress.

As well as the relationship with the neurosurgeon, it was interpreted that participant apprehension was contained due to use of distraction or avoidance techniques by participants and the neurosurgical team during the AC. This is consistent with research proposing that distraction techniques during awake operations can be beneficial for patients. For example, studies have reported that therapeutic hand massage (Kim, Cho, Woo, \& Kim, 2001), hand stroking (Moon \& Cho, 2001), intra-operative music (LePage, Drolet, Girard, Grenier, \& Degagne, 2001), and viewing video (Man et al., 2003) can significantly reduce participant anxiety during surgery. Although beneficial in supporting the general idea of the utility of distraction, these studies were conducted on cataract, spinal, and planned surgeries.

The final superordinate theme, the need for more concrete information prior to surgery, illustrates how participants accepted face-to-face consultation sessions as adequate to gather information about AC. However, when retrospectively considering information provision, participants reported dissatisfaction, particularly with respect to 
concrete information they would have liked to have had to facilitate their understanding of the AC procedure, the information they had to communicate to family and friends, and their understanding of the expected outcomes of the operation. A perceived lack of adequate concrete information is consistent with previous research reporting that patients are unhappy with the amount of information they are given (Lidstone et al., 2003). Insufficient information may affect understanding during the awake operation (Moritz-Gasser \& Duffau, 2010).

In the current study it was interpreted that at the time of AC participants avoided seeking further information as a self-preservation strategy, and instead they relied on their relationship with the neurosurgeon and consultation sessions. This is consistent with research exploring the behaviour of patients with low grade brain tumours (Edvardsson \& Ahlstrom, 2005). However, this finding is inconsistent with the Khu et al. (2009) study, which reported that participants who had experienced AC sought information through the neurosurgery team as well as the internet.

Differences in participant reports illustrate the individuality of the $\mathrm{AC}$ experience. For this reason improvements in information provision should exercise patient choice, that is, patients should have the choice to decide how much information they would like to have, and they can decide the 'dose' and the timing of accessing relevant information. However, to help patients make an informed decision, concrete information must be accessible and, as such, further research is required to determine the preferences of brain tumour patients regarding the format and content of this information (NICE, 2006).

The relationship with the neurosurgeon was reported as crucial to the patient experience of AC. Although the emphasis on the clinician (Chibnall \& Tait, 1995) is reported in other research literature (e.g., in back pain), this has not been extensively studied in previous AC research. The importance of the neurosurgeon has been alluded to in one previous thematic analysis study exploring the patient experience of AC in Canada (Khu et al., 2009), but the centrality of this theme around which other factors are organized is a novel contribution of the present study. The importance of the relationship with the neurosurgeon is consistent with a wider emphasis on the surgeon-patient (Axelrod \& Dorr Goold, 2000), neurosurgical team-patient (Leinonen, Leino-Kilpi, \& Jouko, 1996), and clinician-patient (Chibnall \& Tait, 1995) relationship. The emphasis on the surgeon (Axelrod \& Dorr Goold, 2000) is thought to be attributable to the fact that more operations are now conducted awake, involving the surgeon in building a relationship and communicating with the patient.

It is important to consider the effect this focus may have on the neurosurgeon. Thus, if the neurosurgeon does not have the skills to build the relationship, and the patient does not understand the procedure, the current findings amalgamated with past literature suggest that apprehension prior to the experience, and during the AC procedure may increase (Black, 1998; Lepola, Taljamo, Aho, \& Louet, 2001; Sarang \& Dinsmore, 2003). This places pressure on upcoming and practicing neurosurgeons to develop relationships with patients through the use of therapeutic skills (Axelrod \& Dorr Goold, 2000; Hassett, Zinnerstrom, Nawotniak, Schimpfhauser, \& Dayton, 2006).

Recognizing the importance of facilitating the development of therapeutic skills is crucial, considering that surgeons who were completing their training tended to overemphasize their own communication skills when asked to self-rate, in comparison to clinician ratings given by their patients (Goldstein \& Goedhart, 1973). In order to fulfil a communicative role, neurosurgeons may require further training in communication and empathy (Axelrod \& Dorr Goold, 2000; Larkin et al. 2010; NICE, 2006; Shapiro, 2002), as recognized through the Girgis, Sanson-Fisher, and McCarthy (1997) study. One-third 
of the sample of 143 neurosurgeons reported being 'not' or 'not at all' competent at increasing patients' ability to remember what they were told or to discuss their anxieties about their condition. $13.3 \%$ reported a lack of competence in breaking bad news. This suggests that neurosurgeons themselves believe that further skills in communication and interaction are required, directing the need for the development of formal training or better evaluation of non-technical skills on entry to surgical training (Yule, Flin, PatersonBrown, \& Maran, 2006).

This concern has been recognized. For example, Yule et al. (2006) reported that communication has 'not yet been taken seriously in surgery' (p. 140) and the Royal College of Surgeons have highlighted the need for excellent communication skills in the 'Good Surgical Practice' guidelines (Royal College of Surgeons of England, 2002). The University of Massachusetts has also successfully developed a human factors curriculum for upcoming neurosurgeons (Larkin et al., 2010). The findings in the current study support these developments.

\section{Strengths and limitations}

The current study is the first in the UK to explore the experience of AC using IPA methodology. This extends the small evidence-base, adding to neurosurgeon understanding, as well as, for the first time in AC studies, emphasizing the importance of the neurosurgeon's communication skills to facilitate their relationship with the patient.

Two key limitations of the current study have been recognized. First, no attempt was made to find out the reasons why potential participants chose not to take part in the study, nor why one participant withdrew. Second, data were collected from participants between 5 months and 4 years following the AC experience. This could explain the contrast between the findings in the current study and previous literature, specifically that reporting a less satisfactory experience immediately after awake surgery (Palese et al., 2008). Each is important to consider when considering transferring findings across populations.

\section{Conclusions}

We believe this study adds to the understanding of the patient experience of AC by extending on findings reported in previous research through the core theme: relationship with the neurosurgeon. It was interpreted that this relationship had an impact on the decision to have the AC, on participants' levels of apprehension during the operation, and on the acceptance of the concrete information given. Implications for neurosurgery departments include more consideration for the skills of the neurosurgeon, a more indepth understanding of self-preservation strategies for patients, and better provision of written information. Being aware of the implications may facilitate positive AC experiences in the future, as well as helping future patients to understand how to prepare for the operation they are about to undertake.

\section{References}

Axelrod, D. A., \& Dorr Goold, S. (2000). Maintaining trust in the surgeon-patient relationship: Challenges for the new millennium. Archives of Surgery, 135, 55-61.

Bernstein, M. (2001). Outpatient craniotomy for brain tumor: A pilot feasibility study in 46 patients. The Canadian Journal of Neurological Sciences, 28(2), 120-124. 
Black, S. (1998). Comments. Neurosurgery, 42, 35.

Blanshard, H. J., Chung, F., Manninen, P. H., Taylor, M. D., \& Bernstein, M. (2001). Awake craniotomy for removal of intracranial tumour: Considerations for early discharge. Anaesthesia and Analgesia, 92, 89-94. doi:10.1097/00000539-200101000-00018

Callesen, T., Bech, K., \& Kehlet, H. (2001). One-thousand consecutive inguinal hernia repairs under unmonitored local anaesthesia. Anesthesia and Analgesia, 93(6), 1373-1376. doi:10.1097/00000539-200112000-00004

Canam, C. (1993). Common adaptive forms facing parents of children with chronic conditions.

Journal of Advanced Nursing, 12, 671-676. doi:10.1046/j.1365-2648.1993.18010046.x Chibnall, J. T., \& Tait, R. C. (1995). Observer perceptions of low back pain: Effects of pain report and other contextual factors. Journal of Applied Social Psychology, 25, 418-439.

Costello, T. G., \& Cormack, J. R. (2004). Anaesthesia for awake craniotomy: A modern approach. Journal of Clinical Neuroscience, 11(1), 16-19. doi:10/1016/j.jocn.2003.09.003

Croyle, K. L., Troster, A. L., Fields, J. A., Straits-Troster, K. A., Lyons, K. E., \& Pahwa, R. (2003). Presurgical coping, depression, and quality of life in persons with Parkinson's disease. Journal of Clinical Psychology in Medical Settings, 10(2), 101-107. doi:10.1023/A:1023342021244

Crumlish, C. M. (1994). Coping and emotional response in cardiac surgery patients. Western Journal of Nursing Research, 16(1), 57-68. doi:10.1177/019394599401600105

Danks, R. A., Aglio, L. S., Gugino, L. D., \& Black, P. M. (2000). Craniotomy under local anaesthesia and monitored conscious sedation for the resection of tumors involving eloquent cortex. Journal of Neuro-Oncology, 49, 131-139. doi:10.1023/A:1026577518902

Danks, R. A., Rogers, M., Aglio, L. S., Gugino, L. D., \& Black, P. M. (1998). Patient tolerance of craniotomy performed with the patient under local anaesthesia and monitored conscious sedation. Neurosurgery, 42(1), 28-36. doi:10.1097/00006123-199801000-00006

DeAndres, J., Valia, J. C., Gil, A., \& Bolinches, R. (1995). Predictors of patient satisfaction with regional anaesthesia. Regional Anaesthesia, 20(6), 498-505.

Edvardsson, T., \& Ahlstrom, G. (2005). Illness-related problems and coping among persons with low-grade glioma. Psycho-Oncology, 14(9), 728-737. doi:10.1002/pon.898

Folkman, S., \&Moskowitz,J. T. (2004). Coping: Pitfalls and promise.Annual Review ofPsychology, 55, 745-774. doi:10.1146/annurev.psych.55.090902.141456

Girgis, A., Sanson-Fisher, R. W., \& McCarthy, W. H. (1997). Communicating with patients: Surgeons perceptions of their skills and need for training. Australian and New Zealand Journal of Surgery, 67, 775-780. doi:10.1111/j.1445-2197.1997.tb04578.x

Goebel, S., Nabavi, A., Schubert, S., \& Mehdorn, H. M. (2010). Patient perception of combined awake brain tumor surgery and intraoperative $1.5 \mathrm{~T}$ magnetic resonance imaging: The Kiel experience. Neurosurgery, 67(3), 594-600. doi:10.1227/01.NEU.0000374870.46963.BB

Goldstein, A. P., \& Goedhart, A. (1973). The use of structured learning for empathy enhancement in paraprofessional psychotherapists. Journal of Community Psychology, 1, 168-173. doi:10.1002/1520-6629(197304)1:2<168::AID-JCOP2290010204>3.0.CO;2-9

Hassett, J. M., Zinnerstrom, K., Nawotniak, R. H., Schimpfhauser, F., \& Dayton, M. T. (2006). Utilization of standardized patients to evaluate clinical and interpersonal skills of surgical residents. Surgery, 140(4), 633-639. doi:10.1016/j.surg.2006.07.014

Khu, K. J., Doglietto, F., Radovanovic, I., Taleb, F., Mendelsohn, D., Zadeh, G., \& Bernstein, M. (2009). Patient's perceptions of awake and outpatient craniotomy for brain tumour: A qualitative study. Journal of Neurosurgery, 10, 1-5. doi:10.3171/2009.6.JNS09716

Kim, M. S., Cho, K. S., Woo, H. M., \& Kim, J. H. (2001). Effects of hand massage on anxiety in cataract surgery using local anaesthesia. Journal of Cataract and Refractive Surgery, 27(6), 884-890. doi:10.1016/S0886-3350(00)00730-6

Lanier, W. L. (2001). Brain tumour resection in the awake patient. Mayo Clinical Proceedings, 76, 670672. doi:10.1016/S0025-6196(11)64995-1

Larkin, A. C., Cahan, M. A., Whalen, G., Hatem, D., Starr, S., Haley, H....Quirk, M. (2010). Human emotion and response in surgery (HEARS): A simulation-based curriculum for communication 
skills, systems-based practice, and professionalism in surgical residency training. Journal of American College of Surgeons, 211(2), 285-292. doi:10.1016/j.jamcollsurg.2010.04.004

Lazarus, R. (1993). Coping theory and research: Past, present and future. Psychosomatic Medicine, 53 , 234-237. doi:10.1.1.115.9665

Lazarus, R. S., \& Folkman, S. (1984). Stress, appraisal and coping. New York: Springer.

Leinonen, T., Leino-Kilpi, H., \& Jouko, K. (1996). The quality of intraoperative nursing care: The patient's perspective. Journal of Advanced Nursing, 24(4), 843-852. doi:10.1046/j.1365-

2648.1996.26224.x

Lepage, C., Drolet, P., Girard, M., Grenier, Y., \& DeGagne, R. (2001). Music decreases sedative requirements during spinal anesthesia. Anesthesia and Analagesia, 93(4), 912-916. doi:10.1097/00000539-200110000-00022

Lepola, I., Taljamo, M., Aho, R., \& Louet, T. (2001). Being a brain tumour patient: A descriptive study of patient experiences. Journal of Neuroscience Nursing, 33(3), 143-146.

Lidstone, V., Butters, E., Seed, P. T., Sinnott, C., Beynon, T., \& Richards, M. (2003). Symptoms and concerns amongst cancer outpatients: Identifying the need for specialist palliative care. Palliative Medicine, 17, 588-595. doi:10.1191/0269216303pm814oa

Lincoln, Y. S., \& Guba, E. G. (1985). Naturalistic Enquiry. Newbury Park, CA: Sage Publications. Man, A. K., Yap, J. C., Kwan, S. Y., Suen, K. L., Yip, H. S., \& Chen, P. P. (2003). The effect of intra-operative video on patient anxiety. Anaesthesia, 58(1), 64-68. doi:10.1046/j.13652044.2003.02788_4.x

Manninen, P. H., Balki, M., Lukitto, K., \& Bernstein, M. (2006). Patient satisfaction with awake craniotomy of tumour surgery: A comparison of remifentanil and fentanyl in conjunction with propofol. Neurosurgical Anaesthesia, 102, 237-242. doi:10.1213/01.ANE.0000181287.86811.5C

McDougall, R., Rosenfeld, J., Wrennall, J., \& Harvey, A. S. (2001). Awake craniotomy in an adolescent. Anaesthesia and Intensive Care, 29, 423-425.

Meyer, F. B., Bates, L. M., Goerss, S. J., Friedman, J. A., Windschitl, W. L., Duffy, J. R....O’Neill, B. P. (2001). Awake craniotomy for aggressive resection of primary gliomas located in eloquent brain. Mayo Clinic Proceedings, 76, 677-687. doi:10.4065/76.7.677

Moon, J. S., \& Cho, K. S. (2001). The effects of handholding on anxiety in cataract surgery patients under local anaesthesia. Journal of Advanced Nursing, 35(3), 407-415. doi:10.1046/j.13652648.2001.01855.x

Moritz-Gasser, S., \& Duffau, H. (2010). Psychological consequences of awake brain tumour surgery. Psycho-Oncologie, 4(2), 96-102. doi:10.1007/s11839-010-0256-4

National Institute for Clinical Excellence. (2006). Improving outcomesfor people with brain and other CNS tumours - The manual. London, UK: NICE Cancer Service Guidance.

Palese, A., Skrap, M., Fachin, M., Visioli, S., \& Zannini, L. (2008). The experience of patients undergoing awake craniotomy: In the patients' own words - A qualitative study. Cancer Nursing, 31(2), 166-172. doi:10.1097/01.NCC.0000305699.97625.dc

Royal College of Surgeons of England. (2002). Good Surgical Practice. London, UK: RCSENG Professional Standards and Regulation.

Sarang, A., \& Dinsmore, J. (2003). Anaesthesia for awake craniotomy - Evolution of a technique that facilitates awake neurological testing. British Journal of Anaesthesia, 90(2), 161-165. doi:10.1093/bja/aeg037

Serletis, D., \& Bernstein, M. (2007). Prospective study of awake craniotomy used routinely and non selectively for supratentorial tumors. Journal of Neurosurgery, 10, 1-6. doi:10.3171/JNS07/07/0001

Shapiro, J. (2002). How do physicians teach empathy in the primary care setting? Academic Medicine, 77(4), 323-328. doi:10.1097/00001888-200204000-00012

Smith, J. A. (1996). Beyond the divide between cognition and discourse: Using interpretative phenomenological analysis in health psychology. Psychology \& Health, 11, 261-271. 
Smith, J. A., Flowers, P., \& Larkin, M. (2009). Interpretative phenomenological analysis: Theory, method and research. London, England: Sage Publications.

Spijker, A., Trijsburg, R. W., \& Duivenvoorden, H. J. (1997). Psychological sequelae of cancer diagnosis: A meta-analytic review of 58 studies after 1980. Psychosomatic Medicine, 59(3), 280-293.

Tonn, J. C. (2007). Awake craniotomy for monitoring language function: Benefits and limits. Acta Neurochirurgica (Wien), 149, 1197-1198. doi:10.1007/s00701-007-1368-x

Whittle, I. R., Midgley, S., Georges, H., Pringle, A. M., \& Taylor, R. (2005). Patient perceptions of "awake" brain tumour surgery. Acta Neurochirurgica, 147(3), 275-277. doi:10.1007/s00701-004$0445-7$

Yardley, L. (2000). Dilemmas in qualitative health research. Psychology \& Health, 15(2), 215-228. doi:10.1080/08870440008400302

Yule, S., Flin, R., Paterson-Brown, S., \& Maran, N. (2006). Non-technical skills for surgeons in the operating room: A review of the literature. Surgery, 139, 140-149. doi:10.1016/j.surg.2005.06.017 